\title{
Friend or foe! The Professionalisation Agenda: Teacher Educators In The Lifelong Learning Sector (LLS)
}

\author{
Charmaine Brown \\ School of Education
}

\section{Introduction}

As a teacher educator I am affected by the professionalisation agenda which governs the reforms in Initial Teacher Training (ITT) in the Lifelong Learning Sector (LLS). The increased number of tasks I am now required to perform has increased significantly from 1990, when I first started training teachers on a range of post-compulsory teaching and professional training programmes. I am now required to meet a set of professional competencies and specific pedagogical skills (generic and specialist) that comply with national standards for teachers and trainers in the sector. This includes recording evidence of Professional Formation as part of Continuous Professional Development (CPD) to gain Qualified Teacher Learning and Skills (QTLS) status (Institute for Learning, 2007). Institutions that deliver ITT programmes are now instrumental in ensuring that all teacher educators are equipped to train teachers to the required standards governed by the policy initiatives.

This paper discusses the paradox that, despite the discussions about professionalisation, many lecturers and teacher trainers interviewed as part of my small scale research in 2009 have experienced a significant deterioration in working conditions. They see the increase in administration as negative not positive and feel that they are being de-skilled. Lack of job security is also a major concern, as $90 \%$ of the research sample work part-time or on short-term or fixed term contracts. All interviewees concluded that the changes to the sector since incorporation (1992) have 'proletariarised' rather than professionaliaed their work status as teachers strive to meet externally set targets.

The next section gives an overview of a selection of policies relevant to the professionalisation agenda. Equipping Our Teachers For the Future (2004); Prosperity for All in the Global Economy: World Class Skills (2006); The Independent Review of Higher Education Funding and Student Finance (2009); and The Wolf Review (2011) are used as references for issues raised throughout this paper.

\section{Policy initiatives and their relevance to ITT}

Equipping our Teachers for the Future (2004) has been instrumental in reforming professional standards in ITT for LLS. The introduction of a new funding regime and the Sector Skills Council, Lifelong Learning UK (LLUK), from April 2007 enabled the review of existing standards and the introduction of additional new national standards initiated by the Further Education and National Training Organisation 
(FENTO) since 1999. From September 2007, trainee and in-service teachers could apply to gain Qualified Teacher in Learning and Skills (QTLS) status endorsed by the Institute for Learning (IfL). The IfL was set up as an independent monitoring body to endorse the professional standards in teachers/ trainers in LLS gained through a process of recording evidence for professional formation. QTLS aims to ensure that all students in further education (FE) are taught by teachers and trainers who are both experienced in their subject(s) and skilled at teaching.

Prosperity for All in the Global Economy: World Class Skills (2006) was introduced by Lord Leitch as a response to the need to examine the UK's long-term skills needs. It set out ambitious goals for 2020 which, if achieved, would supposedly make the UK a world leader in skills. The Rt Hon. Dr Vince Cable MP, Secretary of State for Business, Innovation and Skills, developed and extended the prerequisites needed to achieve this agenda in the recent review of the sector outlined in Skills for Sustainable Growth (2010). The implications for ITT are to ensure that all students in FE are taught by teachers and trainers who are both experienced in their subject and skilled at teaching. The Standards Verification UK (SVUK) endorsement of the PGCE at levels 5-7, and the introduction of the Master's in Teaching award, is also intended to signal the need to update the required level of national teaching qualifications (PGCE) previously endorsed at level 4 by FENTO (1999).

The Independent Review of Higher Education Funding and Student Finance (2009) was launched by Lord Browne. As readers will be familiar, the review was tasked with making recommendations to the Government on the future of fees policy and financial support for full- and part-time undergraduate and postgraduate students. The proposals which affect ITT state:

All new academics with teaching responsibilities should undertake a teaching qualification

New providers will be allowed to offer higher education teaching

The independent review models an $80 \%$ cut in the teaching grant to universities, showing a slight drop in their overall income if all universities charged fees of $£ 6,000 \mathrm{pa}$, and a slight rise if they all charged $£ 7,000$ pa.

The Wolf Review (2011) was commissioned by the Rt Hon. Michael Gove MP, Secretary of State for Education, to carry out an independent review of vocational education in the UK. Wolf's recommendations on the need for "brilliant vocational teaching" have been warmly received by the IfL as representative of the sector. Further recommendations for FE teachers with QTLS status to teach in schools would bring the vision of Equipping Our Teachers (DfES, 2004, 5) one step closer to achieving its notion of FE teachers enjoying parity of esteem with school teachers. 


\section{Professional identity and the role of the FE teacher in the LLS}

Reviews of literature in the field of ITT show that recent government initiatives and reports contain the words 'new professionalism' and 'managerialism' (or variations of them) as themes central to the modernisation of ITT in the LLS. For instance, Robson (1998) describes the complexities of 'Dual Professionalism' as the double layer of skills which FE teachers often possess: the teacher as a specialist in one or more vocational/technical specialist areas combined with another identity of professional teacher. It is therefore possible to identify the notion of the 'technical /vocational teacher', who is often very experienced and has built a career in industry, business or commerce in one or more specialist areas, such as art, fashion, administration, built environment, etc. The IfL $(2011,8)$ has adapted the notion of dual professionalism but presents a Continuing Professional Development (CPD) model which identifies three distinct areas of professional learning:

Vocational and subject-specific knowledge and expertise

Approaches to effective teaching and training

Knowledge of how changes in policy and the local context affect teaching and training.

Although points 1 and 2 are in line with the trends identified in the reforms, point 3 is an additional requirement influenced by the 2004 reforms implemented from 2007.

FENTO has been instrumental in shaping the initial phase of the professionalisation agenda with regards to standardising the qualifications and training in the sector. Since 2001 legislation has required a centralised approach to quality assurance with the endorsement of FENTO, its successors, Lifelong Learning UK (LLUK) and currently, Standards Verification UK (SVUK). The role of the IfL as an 'independent' professional body is compromised due to its remit to support the reforms. The notion of independence is further problematic when the IfL functions as a (government) 'monitor' and 'mediator' between teaching professionals and central government.

A contract culture emerges when relationships between government agencies, institutions and students are tied into funding requirements. Contracts are drawn up with the relevant parties who have multiple functions. Examples include teacher educators as 'triple professionals' who have contracts with training providers to train teachers as part of their institution's contract with the funders. Teachers are also in contractual relationships with their institution, their students and the IfL (through membership). Students have contracts with their teachers as representatives of the institution, and also with examination boards etc. The funders have contracts with all parties as justified in the funding methodology. The IfL therefore acts as a 'broker' between central government contracts (for goods and services) and ITT providers. They in turn contract out their courses to teachers who, in turn, contract out their skills to students to facilitate learning. All participants are required to meet targets that ensure continuity of processes at all levels. Diagram 1 presents a model of the interdependent relationships that characterise the contract culture arising from the reforms. It therefore provides a visual illustration of market-led education. 


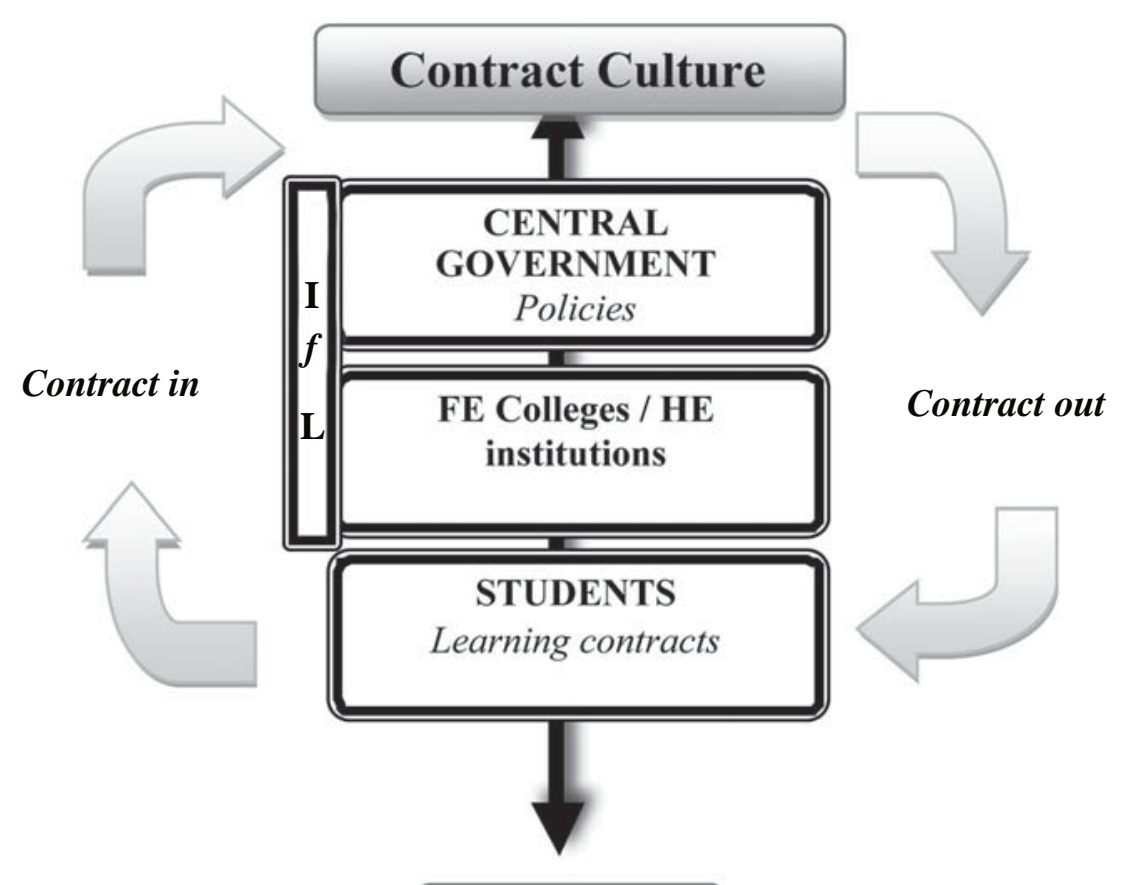

Diagram 1 - 2011

Diagram 1 Professionalisation V proletarianisation - The teaching workforce in LLS

The professionalisation agenda embodied in Equipping Our Teachers for the Future (2004) is not new. Part 1, Chapter 1 of The Further and Higher Education Act (1992) outlines the introduction of national unitary funding councils such as the Higher Education Funding Council (HEFC) and the Further Education Funding Council (FEFC) to centralise the funding of provision in $\mathrm{HE}$ and FE respectively.

The decentralisation of the previous funding mechanisms has increased central government control of the sector. The types of curricula on offer have been radically overhauled with the level of administration required by teachers to comply with the new regulations. The ITT curriculum in FE is less focussed on teaching pedagogy and theory about how people learn. Moreso, it focuses on complying with the administrative requirements of Ofsted and funding bodies. The shift in priority areas of the ITT curriculum has concentrated on modules such as classroom management and mentoring teaching strategies rather than teaching pedagogy, theory and self-reflection. Funding constraints have also made the ITT curriculum more prescriptive. Disgruntled teacher educators often complain about the lack of autonomy in contrast to the IfL which has promoted professional autonomy.

The critical perspective expounded by Bathmaker and Avis (2005) draws on a Marxist analysis of the government's position of power in which the teacher is both oppressed and powerless. The inability of successive government 'think tanks' to include teacher educators as co-investigators in dialogue with policymakers only makes the notion of consultation with pressure groups such as the University and Colleges Union (UCU) and Association of Colleges (AoC) tokenistic. The absence of critical dialogue with policy makers would indicate that teacher educators have been powerless to influence the reforms. 
Further evidence of the powerlessness of teacher educators can be linked to the notion of 'triple professionalism' discussed in the previous section. It provides an accurate description of the 'new professional' teacher caught up in the contract culture of target setting (Diagram 1). In order to critically examine this approach the reader needs to focus on the competencies required for successful completion of the PGCE. Topics such as psychology of learning and teaching, making effective teaching resources and developing specialist teaching areas are subsidiary to the core units. I would argue that the omission of a solid practitioner skills-based training means teachers are 'less equipped' to meet learners' needs. Subjects such as pedagogy, being a reflective practitioner, theory and teaching your specialism, belong to an era which preceded the reforms. Lacking pedagogy, teacher educators have become teacher trainers focused on training to meet funding requirements. Similarly, trainees have less time to engage critically with their own teaching. The Professional Development Record (PDR) records practical elements of teaching and includes target setting to improve practice. The PDR does not contain a section for teacher educators to document models of good practice in practical teaching. It also imposes a maximum of 250 words for trainees to record reflections on teaching practice observations.

\section{Conclusion - the way forward}

Despite my optimism regarding aspects of the professionalisation agenda, the emphasis on competency- based teacher training has been detrimental to the sector. In this article, I have identified some of the relevant policies that have shaped the reforms, presented arguments to demystify the professionalisation agenda fully operational since 2007 , and critically analysed the adverse effects of the reforms. Although the IfL claims to be an independent professional body, it provides a unifying function between the government and colleges as illustrated in Diagram 1. The I $f \mathrm{~L}$ has a monitoring role as a 'broker' between institutions and teacher trainers who deliver ITT. The paper concludes that the changes to the sector since incorporation (1992) have 'proletariarised' rather than professionalised teacher educators' work status.

\section{References}

Bathmaker, A-M., and Avis, J. (2005) Becoming a lecturer in further education in England: the construction of professional identity and the role of communities of practice. Journal of Education for Teaching, 31(1), pp. 47-62.

Browne, X. (2009) The Independent Review of Higher Education Funding and Student Finance. Department for Business, Innovation \& Skills.

Department for Business, Innovation \& Skills (2010) Skills for Sustainable Growth. Department for Business, Innovation \& Skills.

Department for Education and Skills (2004) Equipping our Teachers for the Future: Reforming Initial Teacher Training for the Learning and Skills Sector. DfES.

Leitch (2006) Leitch Review: Prosperity for All in the Global Economy - World Class Skills. HMSO. Robson, J. (1998) A profession in crisis: status, culture and identity in the further education college.

Journal of Vocational Education and Training 50(4), pp. 585-607.

Wolfe (2011) Review of Vocational Education -The Wolf Report. Department for Business Innovation \& Skill 
Compass: The Journal of Learning and Teaching at the University of Greenwich, Issue 